\title{
ACOUSTIC BASES FOR PLACE-FAITHFUL LOAN ADAPTATION
}

\author{
CHRISTOPHER C. ADAM \\ University of New Mexico
}

\author{
AARON W. MARKS \\ University of New Mexico
}

In adapting loanword consonants to native phonology, several strategies are available to languages. Two such strategies are the sacrifice of place to preserve manner (i.e. mannerfaithfulness) and the sacrifice of manner to preserve place (i.e. place-faithfulness). For example, the voiceless dental fricative [ $\theta$ ] of English thank is borrowed into manner-faithful languages as

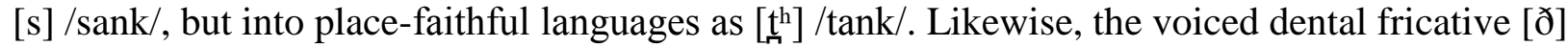
of Classical Arabic faxið 'thigh', is borrowed into manner-faithful languages as [z] /faxiz/, but place-faithful languages as $[\mathrm{d}]$ ] /faxid/.

When languages borrow, they tend to employ one strategy more than the other. In languages with an impoverished fricative inventory and multiple parallel stop sets, it should come as no surprise that the fricative manner is sacrificed in loanwords in order to accommodate faithfulness of place. This is the case in the Sino-Tibetan language Newari, which has a rich series of stops, including parallel stop series with contrastive aspiration, but only two phonemic fricatives, [s] and [š]. Consequently, loan-fricatives [f], [x], [v], and [z] are mapped onto existing

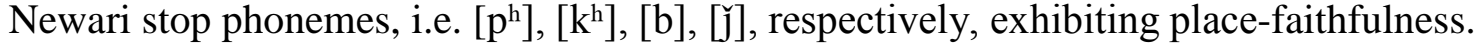

In languages with a richer fricative inventory and no parallel stop sets, it should come as no surprise that the place is sacrificed in loanwords in order to accomodate faithfulness of manner. This is the case with the Indo-Iranian language Persian, which has a rich series of

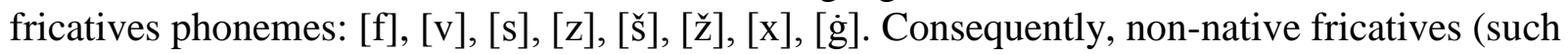
as Arabic $[\theta]$ and $[ð])$ are mapped onto native fricatives ([s] and [z] in the Arabic case) rather than onto stops, thus exhibiting manner-faithfulness.

These typological observations are borne out by the UPSID data set. However, the present study goes a step further than simply making a typological claim.

Place-faithful languages treat imported voiceless fricatives (e.g. [x]) as allophones of voiceless aspirate plosives (e.g. [ $\left.\mathrm{k}^{\mathrm{h}}\right]$ ) when a contrast exists, but do not treat voiced fricatives (e.g. $[\gamma]$ ) as allophones of voiced aspirate plosives (e.g. $\left[\mathrm{g}^{\mathrm{h}}\right]$ ) when a contrast exists; rather, they treat these as allophones of voiced non-aspirate plosives (e.g. [g]).

\begin{tabular}{|c|c|c|c|c|c|}
\hline & IMPORTED & $\begin{array}{l}\text { MAPS TO } \\
\text { HINDI-URDU }\end{array}$ & SOURCE & HINDI-URDU & MEANING \\
\hline \multirow{3}{*}{ 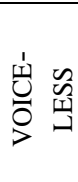 } & $\mathrm{x}$ & $\mathrm{k}^{\mathrm{h}}$ & xun (Persian) & $\mathrm{k}^{\mathrm{h}} \overline{\mathrm{u} n}$ & 'blood' \\
\hline & $\theta$ & $\mathrm{th}^{\mathrm{h}}$ & 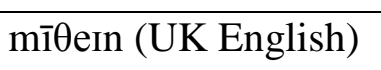 & mīthen $_{n}^{1}$ & 'methane' \\
\hline & $\mathrm{f}$ & $\mathrm{p}^{\mathrm{h}}$ & fayṣlā (Perso-Arabic) & $\mathrm{p}^{\mathrm{h}} \varepsilon s l \bar{a} / \mathrm{f} \varepsilon s \bar{a}^{2}$ & ‘decision’ \\
\hline \multirow{3}{*}{$\begin{array}{l}\text { 总 } \\
\text { Oे }\end{array}$} & 8 & $\mathrm{~g}$ & yalaț (Perso-Arabic) & galant & 'wrong' \\
\hline & ठ & $\mathrm{d}$ & Һєðəı g.æm (English) & hedərər grem ${ }^{3}$ & 'Heather Graham' \\
\hline & $\mathrm{v}$ & $\mathrm{b}$ & vən (Sanskrit) & bən & 'forest' \\
\hline
\end{tabular}

Table 1: Mappings for imported fricatives in Hindi-Urdu

\footnotetext{
${ }^{1}$ Attested in State Hindi News (2011).

${ }^{2}$ The [feslā] variant is typical of Urdu and acrolectic Hindi.

${ }^{3}$ Attested in BBC Hindi (2002) and Nav Bhārat Times (2008).
} 
Table 1 provides a schema for this process in Hindi-Urdu, a place-faithful language with both voiceless and voiced aspirate contrasts. Though the source languages and time periods for the loans differ by many centuries, the same pattern of voiceless fricatives being mapped to voiceless aspirate plosives and voiced fricatives being mapped to voiced non-aspirate plosives provides a recurring pattern which is not by any means negligible.

To support these theoretical findings with quantifiable acoustic measurements, we tested our intuitive hypothesis, which was that the segment mapping occurred on the basis of mean duration. Voiceless fricatives map to voiceless aspirated plosives, and voiced fricatives map to voiced plain plosives, because, for the imported fricative segments (e.g. /x/), the mean duration of the actual target segment (e.g. $\left./ \mathrm{k}^{\mathrm{h}} /\right)$ is closer to it than that of the potential target segment with equal voicing and place but opposite aspiration value (e.g. $/ \mathrm{k} /$ ). Our measurements for the velar series in Hindi-Urdu are given below. This data was obtained by using Praat to measure the duration of consonant tokens in words taken from popular Hindi-Urdu-language media.

\begin{tabular}{|l||l|l|l|l|l|l||}
\hline & {$[\mathrm{k}]$} & {$\left[\mathrm{k}^{\mathrm{h}}\right]$} & {$[\mathrm{x}]$} & {$[\mathrm{g}]$} & {$\left[\mathrm{g}^{\mathrm{f}}\right]$} & {$[\mathrm{\gamma}]$} \\
\hline \hline $\begin{array}{l}\text { Mean duration } \\
\text { (in milliseconds) }\end{array}$ & 56 & 93 & 87 & 62 & 109 & 74 \\
\hline Number of tokens & 33 & 25 & 26 & 24 & 25 & 26 \\
\hline
\end{tabular}

Table 2: Mean duration for velar series segments in Hind-Urdu

Our data sample for this analysis included at least five different speakers for each of five tokens representing each of the five dorsal segments under investigation, which yielded a minimum of 25 tokens (24 for [g]) for each segment, giving a total of more than 150 tokens under analysis.

Statistical analysis of the data showed that the difference in mean duration between $/ \mathrm{k} /$ and $/ \mathrm{x} /$ and between $/ \mathrm{k} /$ and $/ \mathrm{k}^{\mathrm{h}} /$ were highly significant $(\mathrm{p}<0.001)$. The difference between $/ \mathrm{k}^{\mathrm{h}} /$ and $/ \mathrm{x} /$ was not significant $(0.3<\mathrm{p}<0.4)$, indicating that these two segments would be expected to be perceived as having roughly equal duration. Likewise, the difference in mean duration between $/ \mathrm{g}^{\mathrm{h}} /$ and $/ \mathrm{\gamma} /$ and between $/ \mathrm{g}^{\mathrm{h}} /$ and $/ \mathrm{g} /$ were highly significant $(\mathrm{p}<0.001)$. The difference between $/ g /$ and $/ \gamma /$ was not significant $(0.05<\mathrm{p}<0.1)$, again indicating that these two segments should be perceived as having roughly equal durations. These results confirm our hypothesis that voiceless fricatives map in duration to voiceless aspirates, while voiced fricatives map in duration to voiced non-aspirates, based on perception.

For this study, we analyzed only the dorsal segment series $[\mathrm{k}],\left[\mathrm{k}^{\mathrm{h}}\right],[\mathrm{x}],[\mathrm{g}],\left[\mathrm{g}^{\mathrm{h}}\right],[\mathrm{\gamma}]$. However, we believe an analysis of other place series, such as labial $[\mathrm{p}],\left[\mathrm{p}^{\mathrm{h}}\right],[\mathrm{f}],[\mathrm{b}],\left[\mathrm{b}^{\mathrm{h}}\right],[\mathrm{v}]$, will yield similar results.

The not insignificant body of previous research reflects hints of our assumptions but lacks the typological and acoustic support which we bring to the table.

Hock (1991) and Kim (2009) assert that there is a desire on the part of borrowing languages to find a one-to-one mapping of foreign segments onto the native phoneme inventory. Hock (1991:394) further states that the mapping of non-native fricatives onto aspirates is "because the friction noise of these aspirates approximates the acoustic impression of the foreign fricatives”. However, we assert that it is not merely the relative similarity of the imported fricative's spectral characteristics and those of the aspirate's burst, but also, as we have demonstrated above, the relative identity in mean duration between the imported fricative and the native stop phoneme, that determines the mapping of foreign fricatives onto native segments. 
Peperkamp (2004) stresses the phonetic nature of loan adaptations, with which we concur insofar as it coincides with our observations about mapping by segment duration. There actually does appear to be a tendency to map non-native phonemic segments onto native phonemes in a one-to-one fashion; however, that is only part of the story. Typological data supports our hypothesis that phonological mapping actually plays the greater role here in a cross-linguistic context. In addition to maximizing one-to-one mappings, what determines how target phonemes are mapped in the borrowing language is the faithfulness criterion of either place or manner, which is itself determined by the borrowing language's already-existing phoneme inventory. Hock (1991:394) also states that "system-based nativizations like these may be quite rare". However, we have observed that such systematic nativizations do, in fact, occur regularly on any given side of a typological divide, which is itself determined by a given language's inventory.

Boersma and Hamann (2007), on the other hand, do claim that OT structural constraints guide perception. However, it is difficult to substantiate such a claim since it is not based on typologically-informed or empirically-testable phenomena, but rather simply on the ad-hoc base generation mechanism which provides so much of the ammunition for anti-OT attacks. While we support and make use of the mechanisms of OT, we see typology and empirically testable acoustic phenomena as necessary guides to construct a base of constraints.

Kim (2009) also works within the OT framework and even treats many of the same phenomena that we look at, but as with Boersma and Hamann (2007), she deals with a set of constraints that are not informed by typology or acoustics, and moreover many of the claims fail to acknowledge a number of diachronically significant explanations for deviance, such as intermediary vehicle languages, which distort loanword phonological norms.

For this study, we were also interested in the question of whether the preference for manner-faithfulness versus place-faithfulness in a given language could be determined by the structure of that language's overall phoneme inventory. Specifically, we wanted to test whether languages with a higher number of homorganic stop series (e.g. [k $\left.\sim \mathrm{k}^{\mathrm{h}} \sim \mathrm{k}^{\prime}\right]$ ) would also have a higher ratio of overall stop phonemes to overall fricative phonemes, because, as mentioned above, we would expect such languages to show a greater tendency to be place-faithful rather than manner-faithful due to the small number of native fricatives available to map foreign fricatives onto. To test this hypothesis, we engaged Henning Reetz' (n.d.) electronic version of Ian Maddieson's (1984) UPSID database, consisting of the phoneme inventories of 451 languages.

Our analysis procedure was as follows. We sorted all of the phonemes for each language by place, e.g. bilabial versus dental, etc., and by manner, e.g., stop versus fricative. We then subsorted stops into homorganic sets, based on Lindblom and Maddieson's (1988) proposal on what constitutes distinct homorganic sets, e.g. aspirate versus non-aspirate. We then calculated the ratio of stop phonemes to fricative phonemes for each language. Finally, we plotted the correlation between number of homorganic stop series, and stop-to-fricative ratios, across the 420 languages in the set that had native fricative phonemes; for the 31 languages that have no fricative phonemes, we made the fricative value (the denominator in the stop-to-fricative ratio) arbitrarily small, at $0.000001(1 / 1,000,000)$.

For each place in each language, we found that languages with more homorganic sets of stops do indeed have a higher stop-to-fricative ratio than those with fewer homorganic sets of 
stops, with only a few individual outliers. ${ }^{4}$ The full plots, with correlation slopes, are given in tables 3 and 4, below:

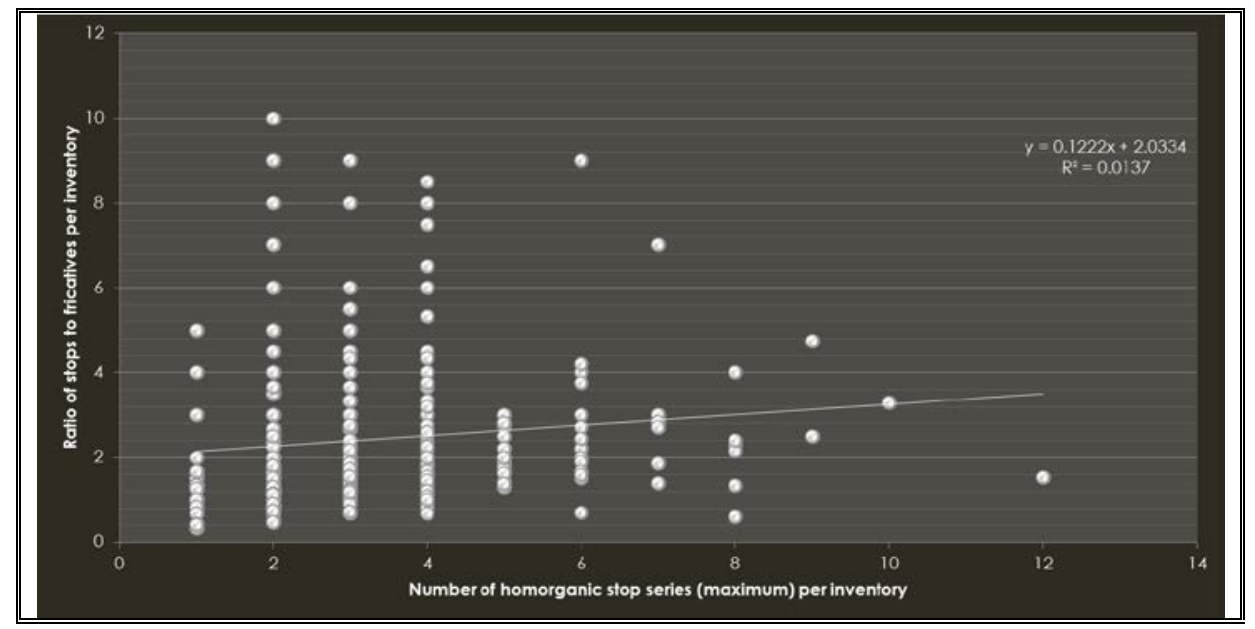

Table 3: Correlation of homorganic stop series quantity to stop/fricative ratio for inventories containing fricatives $(n=420)$

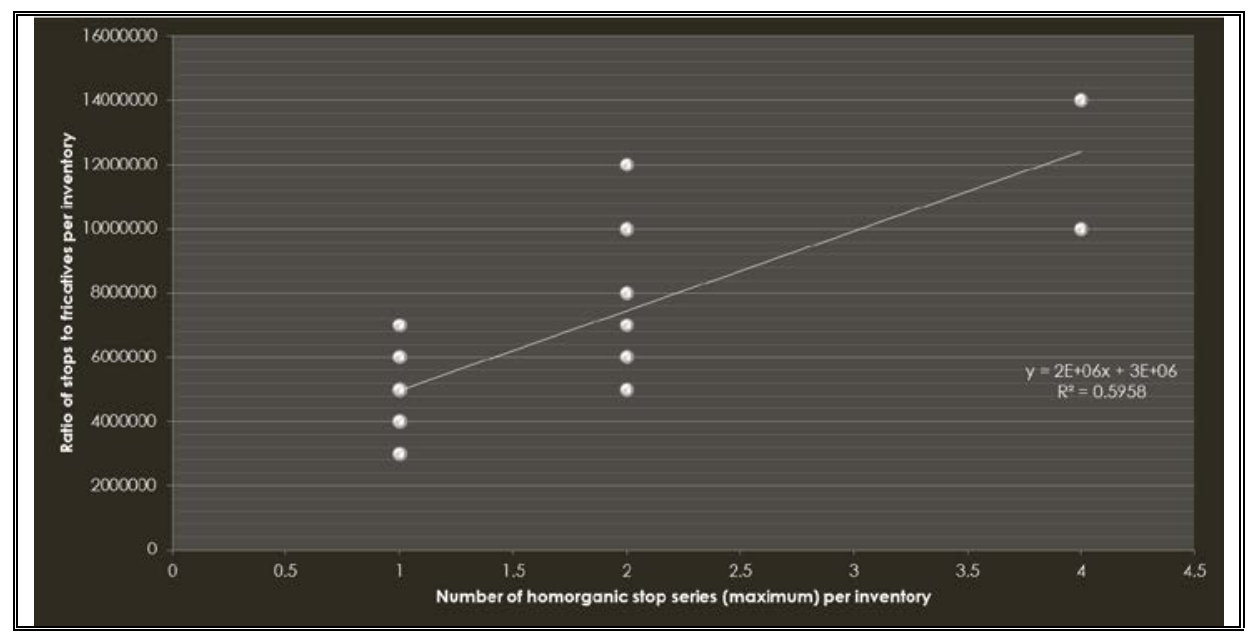

Table 4: Correlation of homorganic stop series quantity to stop/fricative ratio for inventories lacking fricatives $(\mathrm{n}=31)$

Maddieson's (1984; 2006; 2007) earlier tests with the UPSID database appeared to reveal that languages which are richer in one type of distinction are not necessarily more impoverished in another. However, given our data analysis, Maddieson's earlier observations can now be modified to accomodate these results, which he claims are "more fine-grained" than the distinctions he was analyzing (Maddieson, p.c.). We therefore believe that a language's inventory structure should indeed be a predictor of faithfulness type.

Our findings have shown that duration is an important factor in determining how foreign fricatives are mapped onto native segments. They also suggest that inventory structure plays a greater role than previously thought in determining whether languages are place-faithful or manner-faithful. Finally, our findings offer meaningful contributions to Hock's claims about the

\footnotetext{
${ }^{4}$ Notably, many languages of the Caucasus region, which tended to have large numbers of homorganic fricative series that paralleled their stop series.
} 
mapping of foreign fricatives, and to Maddieson's research on compensation in phoneme inventory by demonstrating a correlation between higher number of stop series and lower relative number of fricatives.

\section{REFERENCES}

Boersma, Paul, and Silke Hamann. 2007. Phonological perception in loanword adaptation. Old World Conference in Phonology 4. Rhodes.

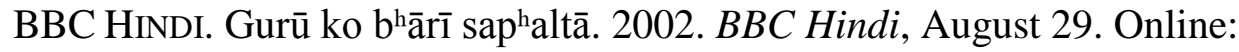
http://www.bbc.co.uk/hindi/news/020828_guru_sz.shtml

Hock, HANS HeInRICH. 1991. Principles of historical linguistics. Berlin, Germany: Walter de Gruyter.

KiM, HyUnSOON. 2009. Korean adaptation of English affricates and fricatives in a feature-driven model of loanword adaptation. In Andrea Calabrese and W. Leo Wetzels (eds.), Loan phonology, 155-180. Philadelphia, PA: John Benjamins Publishing Company.

LINDBLOM, BJORN, and IAN MADDIESON. 1988. Phonetic universals in consonant systems. In Charles N. Li and Larry M. Hyman (eds.), Language, Speech and Mind, 62-78. New York, NY: Routledge.

MAdDIESON, IAN. 1984. Patterns of Sounds. New York, NY: Cambridge University Press.

MADDIESON, IAN. 2006. Correlating phonological complexity: data and validation. Linguistic Typology 10. 108-125.

MADDIESON, IAN. 2007. Issues of phonological complexity: Statistical analysis of the relationship between syllable structures, segment inventories and tone contrasts. In Maria-Josep Solé, Patrice Speeter Beddor and Manjari Ohala (eds.), Experimental approaches to phonology. Oxford University Press, Oxford and New York. 93-103.

NAv BhĀRAt Times. Hedar kī harakat ne hairt mẽ ḍālā. 2008. Nav Bhārat Times, March 18. Online: http://navbharattimes.indiatimes.com/articleshow/2879193.cms

PEPERKAMP, SHARON. 2004. A psycholinguistic theory of loanword adaptations. In Marc Ettlinger, Nicholas Fleisher, and Mischa Park-Doob (eds.) Proceedings of BLS 30. 341352.

ReETZ, HeNNING. n.d. UPSID Info. Web Phonetik. Online: http://web.phonetik.unifrankfurt.de/upsid_info.html

STATE HINDi NEWS. 2011. Ghātak mit ${ }^{\text {hen }}$ ke dușprab ${ }^{\text {hàv }}$ rōkanē kī anūt $t^{\mathrm{h}} \overline{1}$ pahal. State Hindi News, September 14. Online: http://statehindinews.blogspot.com/2011/09/blogpost_7153.html 